\title{
The Immigrant-Native Earnings Gap across the Earnings Distribution
}

\author{
Sara Lemos, University of Leicester ${ }^{1}$
}

June 2014

Using the underexplored, sizeable and long longitudinal 1978-2006 UK Lifetime Labour Market Database (LLMDB) we estimate the immigrant-native earnings gap across the entire earnings distribution. We found that immigrants earn $2.3 \%$ more than natives on average. While the gap was zero at the 30th percentile, it was negative at the bottom of the distribution and positive above the median.

JEL classification: J24 J31 J61 J71 J82 F22.

Keywords: immigration, wages, earnings, earnings-gap, assimilation, UK.

\footnotetext{
${ }^{1}$ University of Leicester, Economics Department, University Road, Leicester LE1 7RH, England, +44 (0)116 252 2480, +44 (0)116 2522908 (fax), sl129@leicester.ac.uk.
} 


\section{Introduction}

There is very limited evidence on the earnings gap between immigrants and natives in the UK (Chiswick 1980; Bell 1997; Dustmann and Fabbri 2005; Dickens and McKnight 2008). This is mainly due to unavailability of suitable data. We use the underexplored, long and sizeable longitudinal UK Lifetime Labour Market Database (LLMDB) between 1978 and 2006 to provide new evidence on this important labour market issue. This is a timely contribution to the UK limited migration literature - and one which informs policymaking.

We estimate the immigrant-native earnings gap across the entire earnings distribution. This allows us to uncover potential earnings gaps at particular points along the distribution that might have been masked by the average gap. This is an improvement over the small existing UK literature, where due to data limitations, no estimation of the gap exploiting a long sample period and a large sample size that allows fine geographical disaggregation is available.

We found that immigrants earn 2.3\% more than natives on average. Across the earnings distribution, the earnings gap was between $-7.4 \%$ and $0.7 \%$ below the median, where nonwhite immigrants are overrepresented, and between $2.4 \%$ and $8.7 \%$ above the median, where white immigrants are overrepresented. This suggests, in contrast with the existing UK literature (Chiswick 1980; Bell 1997; Dustmann and Fabbri 2005), that most immigrants do not seem to suffer an earnings penalty in the labour market. One explanation for the negative gaps at the very bottom of the distribution is that immigrants are more likely than natives to be paid below the minimum wage - potentially because enforcement is a little more lax for immigrants - and this is particularly accentuated for the non-white immigrants.

\section{Data}

The LLMDB is derived from several administrative datasets linked together by a unique individual identifier, the national insurance number (NINo). Because individuals need to produce their NINo in every interaction with the system (pay taxes, receive retirement pension, claim social security benefits, etc.), the LLMDB effectively tracks individuals throughout their lifetime. Thus, the main advantage of the LLMDB is that it is a rich (it contains over 400 variables), long and large longitudinal dataset. It has high levels of accuracy and relatively low levels of attrition (individuals only drop out of the sample if they do not interact with the system for more than 12 months; they re-enter the sample when they next interact with it). Another advantage of the LLMDB is that it permits disaggregation by small geographical levels. This is in contrast with the more widely used Labour Force Survey 
(LFS), where immigration analysis across years and continents or below the regional level is not feasible due to sample size limitations. ${ }^{2}$

Our sample contains workers aged 25 to 64, as is common in the earnings gap literature, earning between $£ 100$ and $£ 1000000$ in any one tax-year (this excludes the self-employed, for whom we do not observe earnings). This results in 433,069 individuals, 45,309 of whom are immigrants, as shown in Table 1, followed between the tax-years 1978 and 2006.

Table 1 shows that natives earn more than immigrants on average. Figure 1 shows the immigrant-native average earnings gap across tax-years (the pooled OLS estimate is -0.132 (0.006)), confirming that on average immigrants earn less than natives during most of the sample period, although the variation is large. Figure 1 also shows that the earnings gap is greater and more negative for male immigrants. Table 1 shows that immigrants at the very bottom of the earnings distribution earn less whereas those at the very top earn more than natives. This is confirmed in Figure 2, which shows the earnings gap across tax-years for several percentiles of the earnings distribution. Whilst immigrants at the bottom of the distribution can earn less than a half of what natives at the bottom of the distribution earn, those at the top can earn up to a quarter more than natives at the top earn. The earnings gap for the lower paid becomes more negative over time, especially after 2003, which coincides with the inflow of low paid Eastern Europeans. In contrast, the earnings gap for the higher paid becomes more positive over time, especially around 2000, following the inflow of high paid North Americans during the 1990s and 2000s. This is also confirmed in Figure 3, which shows that the immigrants' earnings distribution becomes relatively more dispersed over time.

\section{Model Specification}

We use a standard human capital earnings model (see for example, Chiswick 1980, Dustmann and Fabbri 2005) to model the immigrant-native earnings gap where individuals' earnings are a function of characteristics that influence individuals' productivity:

$$
E_{i a t}=\alpha+\beta I_{i}+\lambda X_{i a t}+f_{i}+f_{a}+f_{t}+\varepsilon_{\text {iat }}
$$

\footnotetext{
${ }^{2}$ Table 1 shows that both the LLMDB and the LFS exhibit broadly similar patterns (also see Dustman and Fabbri 2005). The age distribution in both datasets is remarkably similar for natives, though a larger proportion of immigrants is younger in the LLMDB (we tabulate observations, not individuals). This is because the LLMDB better captures low paid immigrants, who tend to be younger. As a result, average earnings are lower in the LLMDB. Importantly, the LLMDB records annual earnings whereas the LFS records weekly earnings in a given week, which are extrapolated for the year ignoring any part-time and/or unemployment spells (which are unknown). As a result, the LFS figures in Table 1 overestimate earnings, which are higher for every percentile of the distribution. The difference is larger at the bottom and smaller at the top of the distribution, confirming that the LLMDB captures more low paid workers. However, although earnings are consistently lower in the LLMDB, the average earnings trend over time is similar (also see Dickens and McKnight 2008).
} 
where $E_{i a t}$ is $\log$ real earnings of individual $i=1, \ldots, 433069$ in area $a=1, \ldots, 49$ and time $t=1978, \ldots, 2006 ; I_{i}$ is an indicator variable that is 1 if the individual is an immigrant; $X_{\text {iat }}$ is a vector of observable individual characteristics; $f_{i}$ is individual fixed effects; $f_{a}$ is area fixed effects; $f_{t}$ is time fixed effects; and $\varepsilon_{\text {iat }}$ is the error term. The interpretation of our coefficient of interest is that immigrants on average earn $\beta \%$ more than natives. ${ }^{3}$

We model area fixed effects using county dummies. This way we control for specific factors in a county (such as more schools, more housing, lower prices, etc.) that may make it more attractive to immigrants or natives or both. We model time fixed effects using tax-year dummies. This way we control for the effect of tax-year specific macroeconomic effects (such as seasonal shocks, national and international macroeconomic shocks, etc.) on earnings.

We also control for observable individual characteristics such as sex, age, age squared number of employed weeks in the year and number of jobs in the year (see Table 1). This way we account for earnings differentials due to workers being for example younger or less experienced in addition to being immigrants. Although we do not observe experience, we control for age, which, albeit imperfectly, captures overall experience to a certain extent.

We control for unobservable individual characteristics by modelling individual fixed effects using a parametric model first introduced by Nakamura and Nakamura (1985) and later used by Chiswick et al. (2005). In this model, individual fixed effects are parameterized using the lagged number of employed weeks in the year and lagged real earnings (instead of using individual dummies). These two lagged variables together embed all the relevant information on unobservable individual characteristics that affects earnings, such as motivation, race, immigrant's age at arrival, education, etc. ${ }^{4}$ This is because these two lagged variables capture individual specific time invariant characteristics that have the same impact on earnings year after year (Nakamura and Nakamura 1985; Chiswick et al. 2005). This way we also circumvent the problem of perfect collinearity between individual dummies necessary to model individual fixed effects $f_{i}$ and our variable of interest $I_{i}$. Controlling for individual

\footnotetext{
${ }^{3}$ More precisely, immigrants on average earn $b=100[\exp (\beta)-1]$ more than natives. As most of our $\beta$ estimates are close to zero, $\beta$ is a good approximation of $b$, so for simplicity we report $\beta$ throughout the paper. Strictly speaking, immigrants on average earn $\beta$ more than natives in logarithmic units (Halvorsen and Palmquist 1980). ${ }^{4}$ Although earnings models commonly control for education, there is an unresolved debate in the immigration literature about what the interpretation of other coefficients in the model should be when controlling for education (Borjas 1999). Excluding education implies that we are comparing the earnings of immigrants and natives, and not the earnings of immigrants and natives with the same education level. This is important because the extent and quality of education varies across countries. Therefore, immigrants and natives with the same education may have different skills and compete for different jobs. Furthermore, immigrants across the education spectrum often suffer skill downgrading due to language or other labour market barriers.
} 
fixed effects enables us to account for any earnings differential due, for example, to workers who are more motivated. Finally, controlling for the lagged number of employed weeks in the year accounts for lower earnings for individuals with historically long spells of unemployment. Including these two lagged variables also allows for the effect of dynamics in the model and alleviates problems arising from serial correlation in the residuals.

We use generalized least square estimation and correct for intragroup serial correlation, as standard errors are assumed to be independent across groups of individuals but not within groups (i.e. for a particular individual over time).

\section{Results}

Table 2 shows that immigrants earn 2.3\% more than natives on average. The implicit approach here was to compare the earnings of all immigrants with the earnings of all natives, which may not be realistic. This is because unskilled immigrants do not compete with skilled natives, for instance. So, an inflow of low paid unskilled immigrants will not directly affect earnings in the high paid highly skilled end of the labour market.

We thus re-estimate our model for several percentiles across the earnings distribution using quantile regression estimation. This is to uncover potentially larger or smaller earnings gaps at particular points along the distribution that might have been masked by the average gap. This is a particularly appealing approach where immigrants concentrate at the bottom and top of the earnings distribution, as it is the case for the UK over the sample period, where immigration has been of predominantly unskilled or highly skilled labour.

Figure 4 and Table 2 show significant immigrant-native earnings gap estimates, nonnegative, except below the $30^{\text {th }}$ percentile. Interestingly, the gap increases monotonically across the distribution: it is respectively $-0.030,0.000,0.014,0.037$ and 0.087 for the $10^{\text {th }}$, $30^{\text {th }}, 50^{\text {th }}, 70^{\text {th }}$ and $90^{\text {th }}$ percentiles. This suggests that the more skilled immigrants are, the more favourable the earnings gap they experience; and the less skilled immigrants are, the larger the earnings penalty they suffer. For example, among the $10 \%$ best paid workers, whom are disproportionately white, immigrants, earn $8.7 \%$ more than natives; whereas among the $10 \%$ worst paid workers, whom are disproportionately non-white, immigrants, earn 3\% less than natives. This in contrast with the existing UK literature (Chiswick 1980; Bell 1997; Dustmann and Fabbri 2005), which reports a gap between $-40 \%$ and $-10 \%$ for non-whites when estimating the average gap using less complete specifications than ours. In our less complete specifications we also find gap estimates as large as $-40 \%$ for those at the bottom of the distribution, which are disproportionately non-white (see Figure 4). 
One particularly appealing explanation for the negative gaps at the very bottom of the distribution is that immigrants are more likely than natives to be paid below the minimum wage - potentially because enforcement is a little more lax for immigrants - and this is particularly accentuated for non-white immigrants.

Our results are in line with the limited international literature, which shows that the immigrant-native gap is also more favourable higher up the distribution for the US (Butcher and DiNardo 2002; Chiswick et al. 2008).

\section{Conclusion}

Our results suggest that there is indeed an immigrant-native earnings gap in the UK between 1978 and 2006. We initially found that immigrants earn 2.3\% more than natives on average. However, this gap varied substantially across the distribution, increasing monotonically, and this variability is masked when solely the average gap is considered. While the gap was zero at the $30^{\text {th }}$ percentile, it was negative at the bottom of the distribution (-7.4\% at the $5^{\text {th }}$ percentile), and positive above the median (between $2.4 \%$ and $8.7 \%$ ). Given that immigration to the UK has been of predominantly unskilled or highly skilled labour, we indeed expected larger gaps at the bottom and top of the distribution.

Thus, on the one hand, the lowest paid immigrants, whom are disproportionately nonwhite, suffer an earnings penalty in relation to the lowest paid natives with comparable individual characteristics. On the other hand, other immigrants do not seem to suffer a penalty - the gap was fairly small in the lower middle of the distribution and was in favour of higher paid immigrants, whom are disproportionately white.

Although our main conclusion is that most immigrants do not seem to suffer an earnings penalty in the labour market, there is indeed an immigrant-native earnings gap at the bottom and top of the earnings distribution in the UK between 1978 and 2006. According to standard human capital theory, non-negligible immigrant-native earnings gap estimates could be due to supply side productivity differentials between natives and immigrants, perhaps unaccounted for in our model. This could be due to imperfect transferability of immigrants' countryspecific human capital or immigrants' skill downgrading due to language or other labour market barriers. Even in the absence of such supply side productivity differentials, there could be demand side explanations for non-negligible earnings gap, such as imperfect information, friction, discrimination or market power of individual firms, again, perhaps, not fully accounted for in our model. Alternatively, institutions might play a role in explaining the negative gaps at the very bottom of the distribution. One appealing explanation is that 
immigrants are more likely than natives to be paid below the minimum wage - potentially because enforcement is a little more lax for immigrants - and this is particularly accentuated for non-white immigrants. These considerations point towards fruitful avenues for future research which inherently raise a wealth of policy implications. 


\section{References}

BELL, B. D. (1997): "The Performance of Immigrants in the United Kingdom: Evidence from the Ghs," The Economic Journal, 107, 333-44.

BORJAS, G. J. (1999): "The Economic Analysis of Immigration," in Handbook of Labor Economics, Vol. 3a, ed. by O. Ashenfelter, and D. Card. Amsterdam: North-Holland, 1697-1760.

BUTCHER, K. F., and J. DINARDO (2002): "The Immigration and Native-Born Wage Distributions: Evidence from United States Censuses," Industrial and Labor Relations Review, 56, 97-121.

CHISWICK, B. R. (1980): "The Earnings of White and Coloured Male Immigrants in Britain," Economica, 47, 81-87

CHISWICK, B. R., A. T. LE, and P. W. MILLER (2008): "How Immigrants Fare across the Earnings Distribution in Australia and the United States," Industrial and Labor Relations Review, 61, 353373.

CHISWICK, B. R., Y. L. LEE, and P. W. MILLER (2005): "Immigrant Earnings: A Longitudinal Analysis," Review of Income and Wealth, 51, 485-503.

DICKENS, R., and A. MCKNIGHT (2008): "Assimilation of Migrants into the British Labour Market," CASE Discussion Paper, 133.

DUSTMANN, C., and F. FABBRI (2005): "Immigration in the British Labour Market," Fiscal Studies, 26, 423-470.

HALVORSEN, R., and R. PALMQUIST (1980): "The Interpretation of Dummy Variables in Semilogarithmic Equations," American Economic Review, 70, 474-475.

NAKAMURA, A., and M. NAKAMURA (1985): The Second Paycheck: A Socioeconomi Analysis of Earnings. New York: Academic Press. 
Table 1 - DESCRIPTIVESTATISTICS

\begin{tabular}{|c|c|c|c|c|c|c|}
\hline \multirow[t]{3}{*}{ VARIABLES } & LLMDB & & LLMDB & & LFS & \\
\hline & \multicolumn{2}{|c|}{ April $1978-$ March 200} & \multicolumn{2}{|c|}{ April $1997-$ March 200} & \multicolumn{2}{|c|}{ January $1997-$ Marc } \\
\hline & Natives & Immigrants & Natives & Immigrants & Natives & Immigrant \\
\hline \multicolumn{7}{|l|}{ I - P OP ULA TION VAR IA B LES } \\
\hline \multicolumn{7}{|l|}{$\%$ aged: } \\
\hline 25 to 34 ye ars old & $31.34 \%$ & $43.83 \%$ & $29.47 \%$ & $43.24 \%$ & $29.06 \%$ & $36.59 \%$ \\
\hline 35 to 64 ye ars old & $68.66 \%$ & $56.17 \%$ & $70.53 \%$ & $56.76 \%$ & $70.94 \%$ & $63.41 \%$ \\
\hline$\%$ of women & $43.43 \%$ & $44.85 \%$ & $46.67 \%$ & $44.37 \%$ & $48.47 \%$ & $47.51 \%$ \\
\hline \multicolumn{7}{|l|}{$\%$ from: } \\
\hline EU (exc e pt A10) & - & $32.20 \%$ & - & $30.99 \%$ & - & $25.66 \%$ \\
\hline A10 & - & $4.03 \%$ & - & $5.41 \%$ & - & $5.43 \%$ \\
\hline Europe (except EU) & - & $3.15 \%$ & - & $3.64 \%$ & - & $2.65 \%$ \\
\hline Asia and Middle East & - & $20.89 \%$ & - & $22.38 \%$ & - & $27.94 \%$ \\
\hline North Americ a & - & $6.09 \%$ & - & $5.04 \%$ & - & $4.63 \%$ \\
\hline La tin Americ a & - & $3.24 \%$ & - & $3.49 \%$ & - & $6.59 \%$ \\
\hline Afric a & - & $13.80 \%$ & - & $16.16 \%$ & - & $21.39 \%$ \\
\hline Austra lasia and Oceania & - & $7.30 \%$ & - & $6.39 \%$ & - & $4.74 \%$ \\
\hline Unknown & - & $9.31 \%$ & - & $6.51 \%$ & - & na \\
\hline Ave ra ge a ge at a rriva l & - & 23.03 & - & 24.43 & - & na \\
\hline Avera ge nb of years since immigra tion & - & 14.73 & - & 13.30 & - & na \\
\hline \multicolumn{7}{|l|}{ \% located in: } \\
\hline East Midlands & $7.64 \%$ & $4.26 \%$ & $7.68 \%$ & $4.28 \%$ & $7.66 \%$ & $4.79 \%$ \\
\hline East of England & $9.50 \%$ & $7.28 \%$ & $9.55 \%$ & $7.62 \%$ & $9.69 \%$ & $9.12 \%$ \\
\hline London & $8.73 \%$ & $29.87 \%$ & $9.03 \%$ & $35.14 \%$ & $9.61 \%$ & $41.76 \%$ \\
\hline North East & $4.46 \%$ & $2.08 \%$ & $4.35 \%$ & $1.88 \%$ & $4.32 \%$ & $131 \%$ \\
\hline North West & $11.72 \%$ & $5.54 \%$ & $11.56 \%$ & $5.57 \%$ & $11.97 \%$ & $5.57 \%$ \\
\hline Northern Ire land & $2.39 \%$ & $1.26 \%$ & $2.51 \%$ & $1.29 \%$ & $2.51 \%$ & $1.22 \%$ \\
\hline S cotland & $9.43 \%$ & $5.16 \%$ & $9.39 \%$ & $4.78 \%$ & $9.03 \%$ & $3.67 \%$ \\
\hline South East & $13.73 \%$ & $12.37 \%$ & $13.93 \%$ & $12.87 \%$ & $13.99 \%$ & $13.87 \%$ \\
\hline South West & $8.79 \%$ & $5.25 \%$ & $8.76 \%$ & $5.09 \%$ & $8.51 \%$ & $5.24 \%$ \\
\hline Wa les & $4.87 \%$ & $2.17 \%$ & $4.79 \%$ & $1.95 \%$ & $4.87 \%$ & $1.80 \%$ \\
\hline West Midlands & $9.16 \%$ & $5.10 \%$ & $9.10 \%$ & $5.26 \%$ & $9.20 \%$ & $6.90 \%$ \\
\hline Yorkshire and the Humber & $8.68 \%$ & $4.12 \%$ & $8.66 \%$ & $4.13 \%$ & $8.66 \%$ & $4.74 \%$ \\
\hline Unknown or Abroad & $0.90 \%$ & $15.55 \%$ & $0.69 \%$ & $10.15 \%$ & - & - \\
\hline \multicolumn{7}{|l|}{ II - LAB OUR MAR KET VARIAB LES } \\
\hline \multicolumn{7}{|l|}{ \% in work: } \\
\hline 1 to 25 we eks in the year & $16.74 \%$ & $26.05 \%$ & $18.84 \%$ & $30.33 \%$ & na & na \\
\hline 26 to 50 we eks in the year & $13.93 \%$ & $18.96 \%$ & $15.45 \%$ & $20.95 \%$ & na & na \\
\hline 51 to 52 weeks in the year & $69.09 \%$ & $54.76 \%$ & $65.55 \%$ & $48.54 \%$ & na & na \\
\hline Ave ra ge number of e mploye d we e ks in the year & 43.18 & 38.52 & 42.10 & 36.40 & na & na \\
\hline Avera ge number of unemployed weeks in the year & 1.37 & 1.39 & 1.03 & 1.17 & na & na \\
\hline Average number of jobs in the year & 1.33 & 1.53 & 1.44 & 1.66 & na & na \\
\hline Ave rage totalactualhours worked in the we e k & na & na & na & na & 36.75 & 37.10 \\
\hline 5th percentile of the log realearnings distribution & 7.60 & 7.27 & 7.65 & 7.25 & 9.22 & 9.15 \\
\hline 10 th percentile of the log realearnings dis tribution & 8.26 & 7.97 & 8.35 & 7.99 & 9.39 & 9.34 \\
\hline 20 th perce ntile of the log rea lea mings dis tribution & 8.87 & 8.65 & 8.93 & 8.68 & 9.59 & 9.57 \\
\hline 30 th percentile of the log rea learnings dis tribution & 9.26 & 9.09 & 9.30 & 9.12 & 9.73 & 9.74 \\
\hline 40th percentile of the log rea learnings dis tribution & 9.50 & 9.40 & 9.55 & 9.43 & 9.86 & 9.88 \\
\hline 50 th percentile of the log rea leamings dis tribution & 9.68 & 9.64 & 9.74 & 9.68 & 9.99 & 10.03 \\
\hline 60 th percentile of the log rea learnings dis tribution & 9.84 & 9.86 & 9.91 & 9.90 & 10.12 & 10.17 \\
\hline 70 th percentile of the log rea learnings dis tribution & 9.99 & 10.06 & 10.08 & 10.13 & 10.26 & 10.32 \\
\hline 80 th percentile of the log rea leamings dis tribution & 10.16 & 10.29 & 10.27 & 10.37 & 10.42 & 10.51 \\
\hline 90 th percentile of the log rea learnings dis tribution & 10.41 & 10.62 & 10.52 & 10.74 & 10.65 & 10.80 \\
\hline Avera ge of the log realearnings dis tribution & 9.48 & 9.45 & 9.55 & 9.50 & 10.00 & 10.04 \\
\hline Standard deviation of the log re a le arnings dis tribution & 0.95 & 1.13 & 0.99 & 1.18 & 0.53 & 0.61 \\
\hline 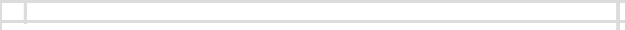 & & & & & & \\
\hline Number of observations & 5053659 & 319427 & 1935699 & 172466 & 507606 & 42230 \\
\hline Number of individuals & 387760 & 45309 & 277532 & 35415 & na & na \\
\hline Average number of times an individual is observed & 15.76 & 18.71 & 24.53 & 25.16 & na & na \\
\hline Average number of observa tions perye ar & 174264 & 11015 & 193570 & 17247 & 50761 & 4223 \\
\hline Source: Litet Ime Labour Market Dat abase and Labour Force S urvey. & & & & & & \\
\hline (1) S a mple includes those aged 25 to 64 employed and earning bet we en $\_100 \mathrm{a}$ & and \pm 10000001 & e year. & & & & \\
\hline (2) LFS figures are courtesy of the DWP. & & & & & & \\
\hline
\end{tabular}




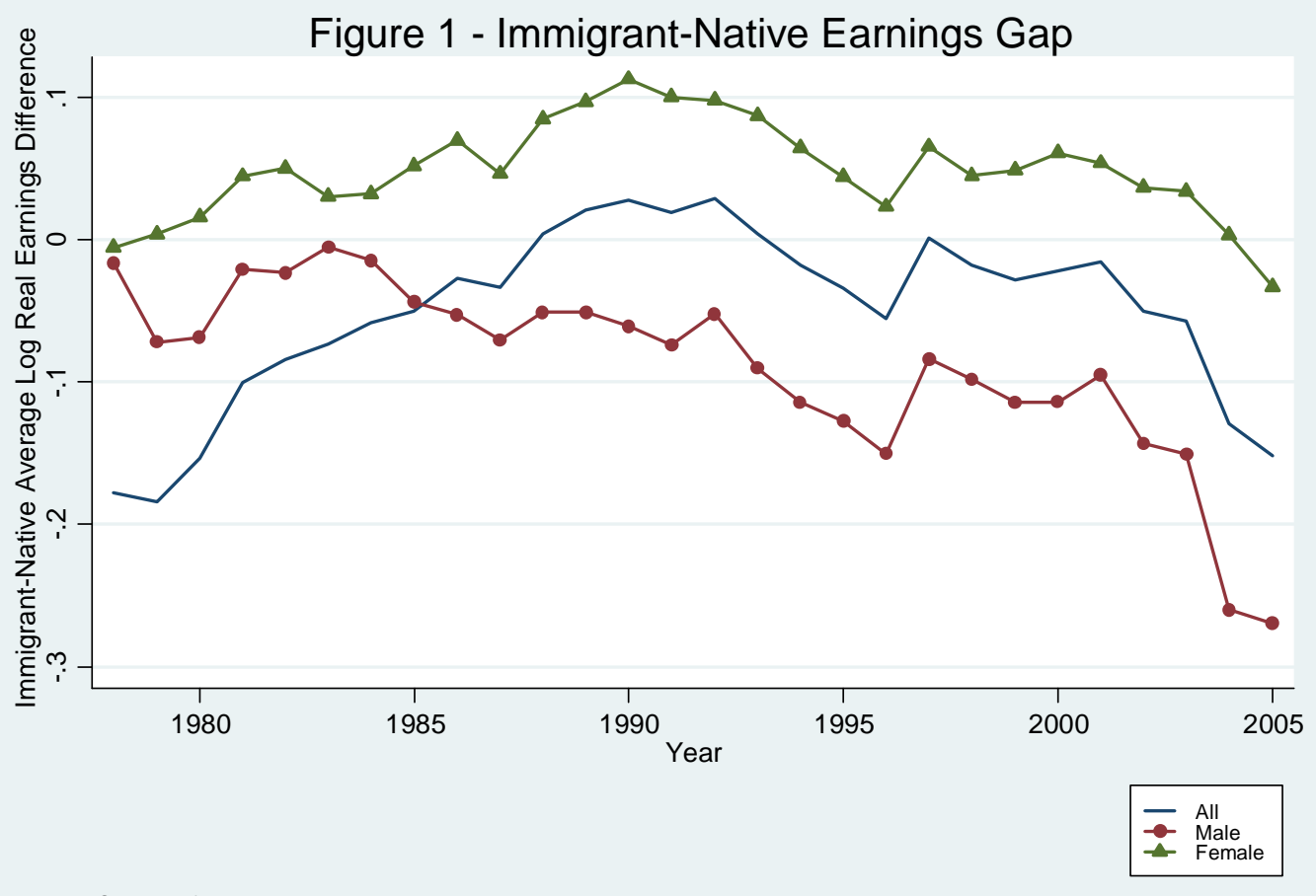

Source: Lifetime Labour Market Database

Figure 2 - Immigrant-Native Earnings Gap Across the Distribution

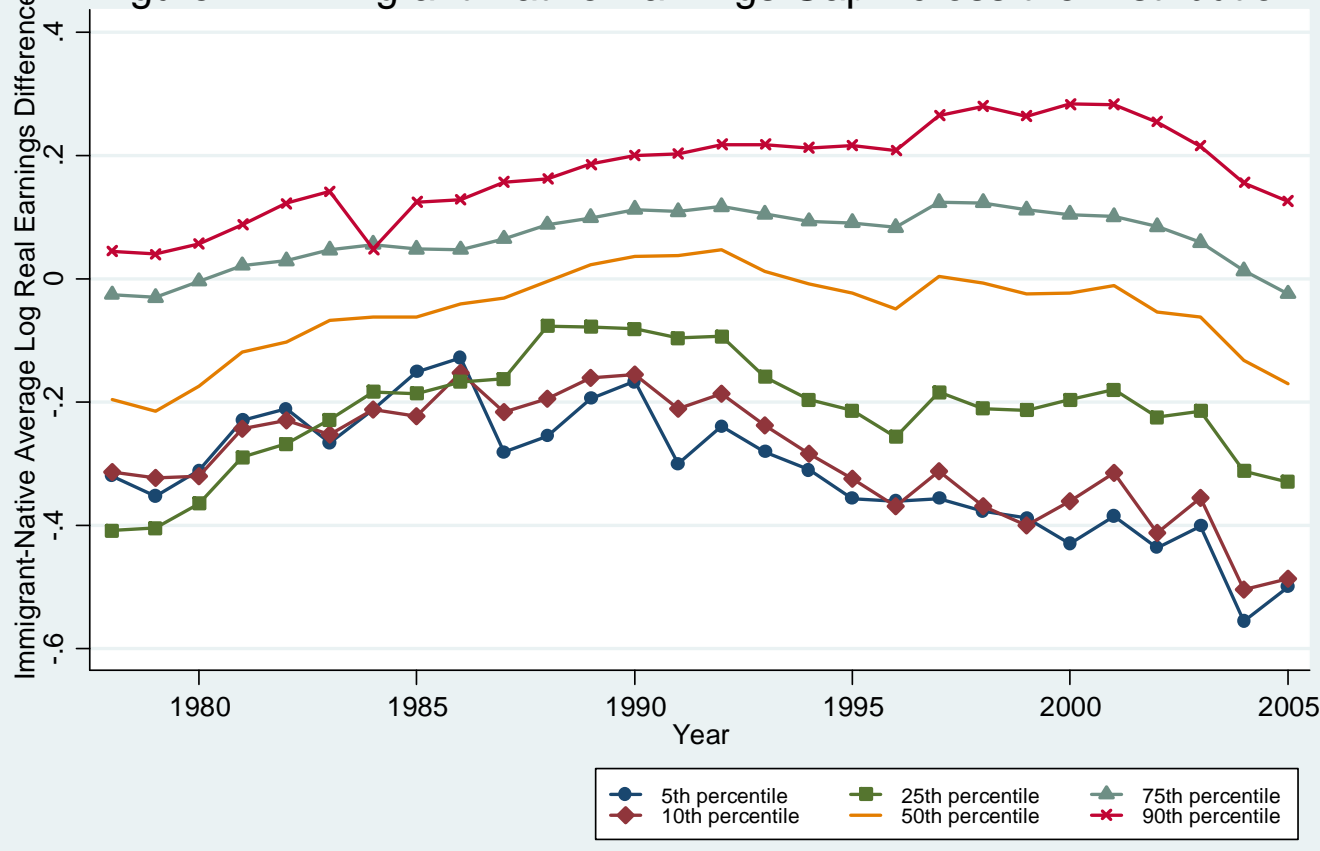

Source: Lifetime Labour Market Database 
Figure 3 - Real Earnings Distribution
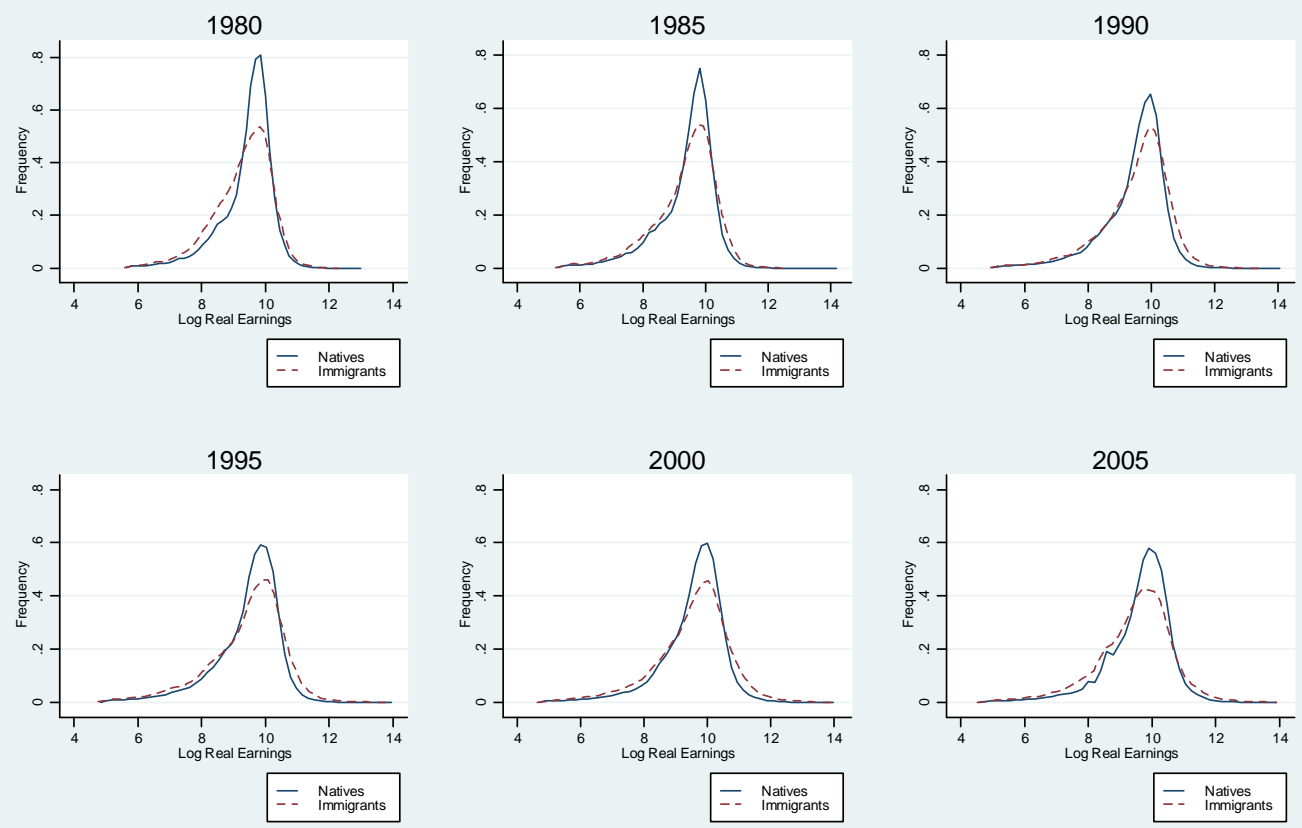

2005

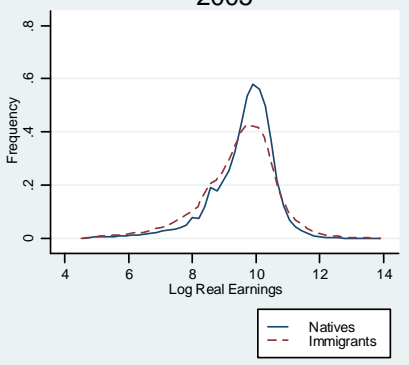

Source: Lifetime Labour Market Database

Figure 4 - Immigrant-Native Earnings Gap Across the Earnings Distribution

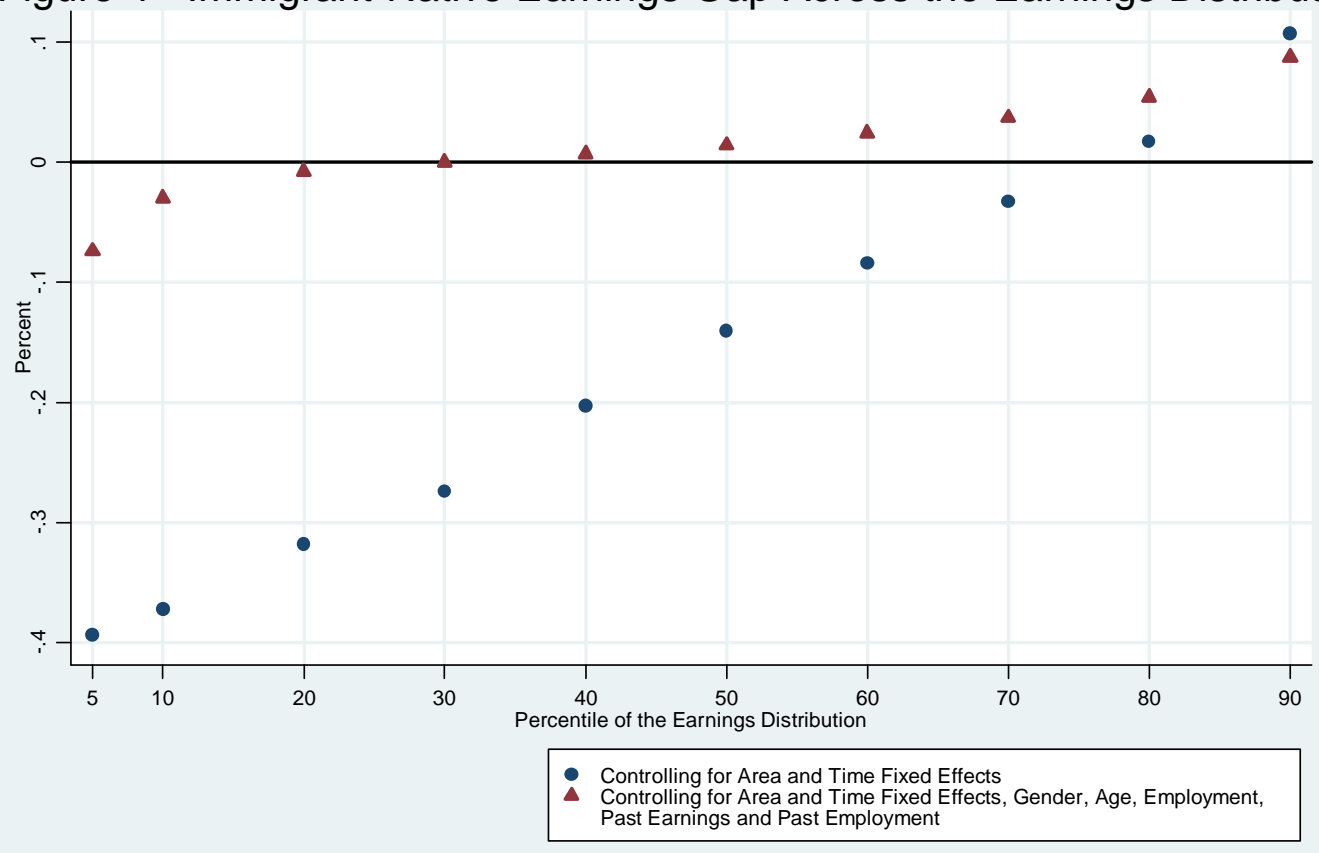

Source: Lifetime Labour Market Database 